\section{THE MANAGEMENT OF TETRALOGY OF FALLOT WITH PULMONARY ATRESIA AND DIMINUTIVE PULMONARY ARTERIES}

Since September 1991, 14 consecutive patients with tetralogy of Fallot, pulmonary atresia, and diminutive pulmonary arteries have undergone staged repair. All patients had multiple aortopulmonary collateral arteries and the ductus arteriosus was absent in 11. Mean sizes of the right and left pulmonary arteries were $2.2 \pm 0.7 \mathrm{~mm}$ and $1.9 \pm 0.8 \mathrm{~mm}$, respectively (range 0.5 to $3.0 \mathrm{~mm}$ ). Eight patients $(57 \%)$ have subsequently received complete repair. Age at initial procedure (shunt, right ventricle-pulmonary artery conduit, or direct aorta-pulmonary artery anastomosis) in this group was $5.3 \pm 6.8$ months. The number of operative procedures to achieve complete repair was $2.9 \pm 0.8$ per patient (range 2 to 4 ). Intraoperative postrepair peak right ventricle-left ventricle pressure ratio was $0.57 \pm 0.17$. Six of 8 patients $(75 \%)$ required additional interventional procedures (mean $1.5 \pm 1.2$ per patient) for angioplasty of peripheral pulmonary artery stenoses, coil embolization of aortopulmonary collateral arteries, or intra* operative insertion of intravascular pulmonary artery stents. Mean follow-up from complete repair was $8.7 \pm 8.3$ months (range 0.5 to 23.8 months) and is complete. There was one in-hospital death at 45 days, and one late cardiac death at $\mathbf{2 0 . 3}$ months. Six patients had initial palliative operations (unifocalization, right ventricle-pulmonary artery conduit, direct aorta-pulmonary artery anastomosis, or transannular outflow patch) but have not undergone complete repair. Age at initial procedure in this group was $27.9 \pm 56.9$ months (range 0.27 to 155 months), and mean follow-up from initial procedure was $10.9 \pm 11.2$ months (range 0 to 31.4 months). The operative mortality rate was $33 \%$ ( 2 of 6 patients). There was one late noncardiac death at $\mathbf{5 . 3}$ months. Three patients are awaiting further intervention or repair. This experience suggests that complete repair is feasible even in patients with extremely diminutive pulmonary arteries ( $\leq 3.0 \mathrm{~mm}$ ). Pulmonary artery growth is facilitated by early (3 to 6 month) establishment of central pulmonary artery flow by right ventriclepulmonary artery conduit (pulmonary arteries $>1.5 \mathrm{~mm}$ ) or by direct ascending aorta-pulmonary artery anastomosis (pulmonary arteries $<\mathbf{1 . 5}$ $\mathbf{m m}$ ). Subsequent interventional catheterization and operative procedures as required for pulmonary artery stenoses and coil embolization of collateral arteries allow continued recruitment of central pulmonary arteries and may obviate or minimize the need for unifocalization procedures. (J Thorac Cardiovasc Surg 1995;110:1521-33)

Francis D. Pagani, MD, PhD ${ }^{\mathrm{a}}$ (by invitation), John P. Cheatham, $\mathrm{MD}^{\mathrm{b}}$ (by invitation), Robert H. Beekman III, $\mathrm{MD}^{\mathrm{c}}$ (by invitation), Thomas R. Lloyd, $\mathrm{MD}^{\mathrm{c}}$ (by invitation), Ralph S. Mosca, MD ${ }^{\mathrm{a}}$ (by invitation), and Edward L. Bove, MD (by invitation), Ann Arbor, Mich., and Omaha, Neb.
From the Section of Thoracic Surgery, Department of Surgery, ${ }^{\text {a }}$ and the Division of Pediatric Cardiology, Department of Pediatrics and Communicable Diseases, ${ }^{\mathrm{c}}$ C. S. Mott Children's Hospital, University of Michigan School of Medicine, Ann Arbor, Mich., and the Division of Pediatric Cardiology, Department of Pediatrics, ${ }^{b}$ University of Nebraska Medical Center, Omaha, Neb.
Read at the Seventy-fifth Annual Meeting of The American Association for Thoracic Surgery, Boston, Mass., April 23-26, 1995.

Address for reprints: Edward L. Bove, MD, F7830 Mott Hospital, Box 0223, University of Michigan, Ann Arbor, MI 48109.

Copyright (C) 1995 by Mosby-Year Book, Inc.

$0022-5223 / 95 \$ 5.00+0 \quad \mathbf{1 2 / 6 / 6 8 1 9 6}$ 
$P^{2}$ atients with tetralogy of Fallot and pulmonary atresia (TOF/PA) represent a heterogeneous group in which the feasibility of complete operative repair and long-term survival is largely dependent on the underlying distribution and size of the pulmonary arteries. ${ }^{1,2}$ In the subgroup of patients with extremely diminutive pulmonary arteries and important associated aortopulmonary collateral arteries, there is no clear consensus regarding the optimal strategies to achieve definitive correction. ${ }^{3}$ Some groups advocate initial unifocalization of important aortopulmonary collateral arteries in an attempt to obtain maximum recruitment of bronchopulmonary segments. ${ }^{4,5}$ However, the long-term reliability of basing pulmonary artery blood flow on aortopulmonary collateral arteries and the overall success of this approach to recruit substantially more bronchopulmonary segments into the central pulmonary circulation have come into question. ${ }^{6-9}$ Technical difficulties, size limitations, the need to implant small peripheral prosthetic conduits, and the probability of the need for complex reoperative procedures all serve to limit the potential usefulness of unifocalization procedures. More recently, there has been less enthusiasm for pursuing initial unifocalization in favor of establishing early right ventricle-central pulmonary artery (RV-PA) continuity as a means to (1) stimulate pulmonary artery growth, (2) improve systemic arterial oxygen saturation, and (3) permit subsequent diagnostic and therapeutic catheterization procedures directed at the pulmonary arteries. ${ }^{10}$ The success of this latter approach has been assisted by recent advances in interventional catheterization procedures and intravascular stent technology. ${ }^{11-15}$ However, many of these patients have central pulmonary arteries that are extremely diminutive in size, often measuring less than 1 or $2 \mathrm{~mm}$ in diameter. The outcome of a management strategy based on an initial operative procedure that establishes antegrade flow in pulmonary arteries this small is unknown.

In this report, we describe the treatment of 14 consecutive patients with TOF/PA and extremely diminutive pulmonary arteries $(\leq 3.0 \mathrm{~mm}$ in diameter) who underwent early operative staged repair with subsequent interventional catheterization techniques to assist in the recruitment and rehabilitation of the pulmonary arteries. The outcome of initial and subsequent operative procedures, the role of interventional catheterization, the potential of achieving complete repair, and the feasibility of avoiding unifocalization procedures are analyzed.
Table I. Associated noncardiac conditions in 14 patients with TOF/PA and diminutive pulmonary arteries

\begin{tabular}{ll}
\hline \multicolumn{1}{c}{ Associated noncardiac condition } & No. \\
\hline DiGeorge syndrome & 4 \\
Dysmorphic features & 3 \\
Renal anomalies & \\
$\quad$ Bilateral renal hypoplasia & 1 \\
$\quad$ Dual collecting system & 1 \\
Seizure disorder & 4 \\
Scoliosis & 2 \\
Intestinal volvulus & 1 \\
Microcephaly & 1 \\
Chromosomal abnormalities & \\
Deletion of long arm of chromosome 22 & 1 \\
Trisomy 9 & 1 \\
\hline
\end{tabular}

Table II. Associated congenital cardiovascular malformations in 14 patients with TOF/PA and diminutive pulmonary arteries

\begin{tabular}{lc}
\hline Associated cardiac malfomation & No. \\
\hline Coronary artery anomalies & 2 \\
Anomalous origin of left subclavian artery & 1 \\
Anomalous course of innominate vein & 1 \\
Double-outlet right ventricle & 1 \\
Congenital aortic stenosis & 1
\end{tabular}

\section{Patients and methods}

Study group. Fourteen consecutive patients with TOF/PA and diminutive pulmonary arteries (central pulmonary arteries $\leq 3.0 \mathrm{~mm}$ in diameter) who underwent staged repair since September 1991 at C. S. Mott Children's Hospital, University of Michigan, were identified by retrospective review of hospital records. There were seven male infants. Mean birth weight was $2.77 \pm 0.58 \mathrm{~kg}$ (range 1.66 to $3.66 \mathrm{~kg}$ ). Four infants were born at less than 38 weeks of gestation (range 32 to 37 weeks). All patients had cyanosis and tachypnea at presentation. Twelve patients (86\%) were first seen within the first 3 days of life, one at 9 days of life, and one at age 5 months. Associated noncardiac conditions are listed in Table I. The most frequent associated noncardiac conditions were DiGeorge syndrome and seizure disorders, each present in $29 \%$ of the patients (4/14). Exclusive of an interatrial level shunt (patent foramen ovale or secundum atrial septal defect) that was present in all patients, associated cardiovascular malformations were present in $43 \%$ of the patients $(6 / 14$, Table II). The aortic arch was right sided in 10 patients $(71 \%)$.

The ductus arteriosus was absent in 11 patients $(79 \%)$. Confluent central pulmonary arteries were present in 13 patients (93\%). Magnetic resonance imaging (MRI) was done preoperatively in 3 patients to investigate the central pulmonary artery anatomy. In two patients, MRI demonstrated the presence of confluent central pulmonary ar- 

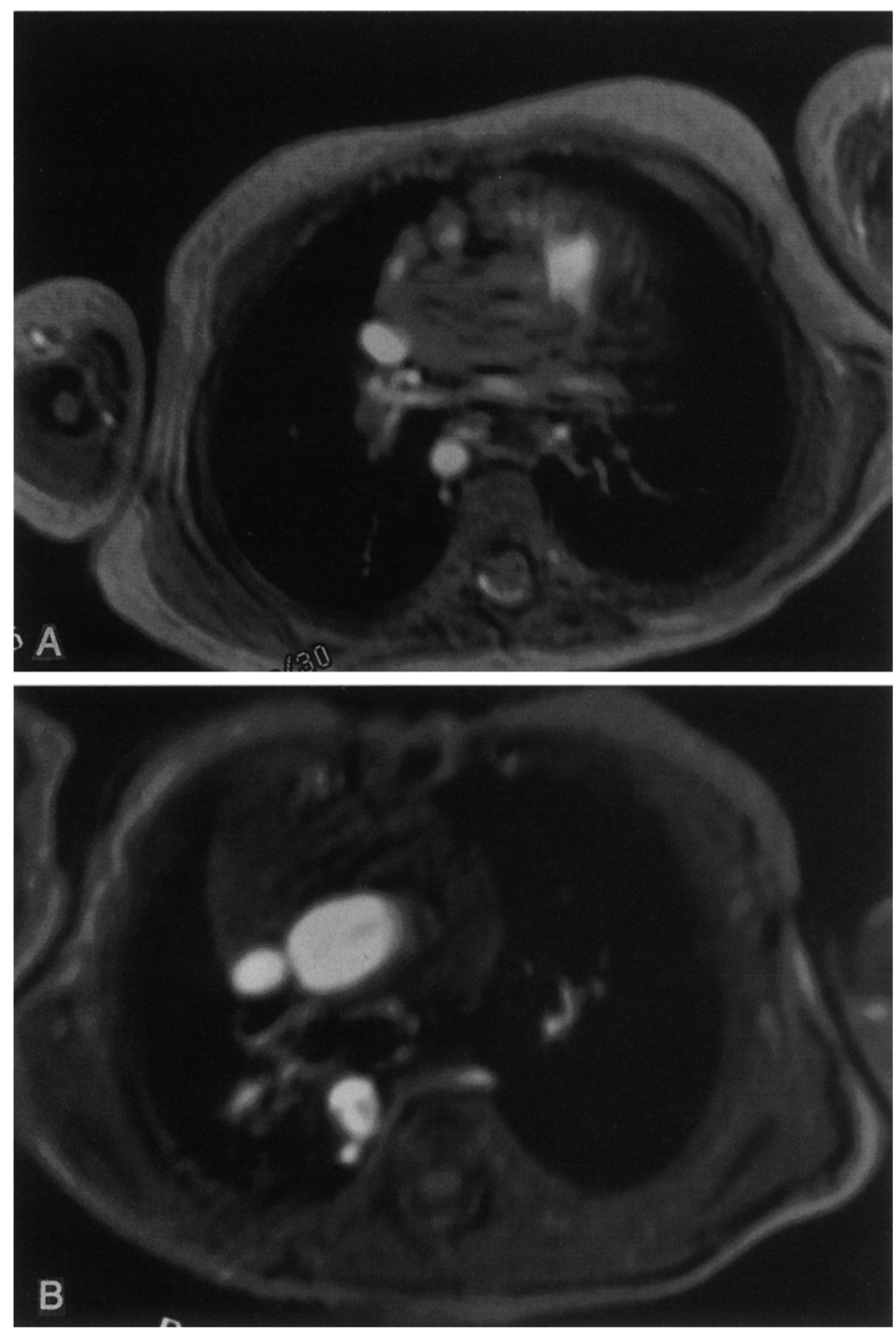

Fig. 1. A, MRI view demonstrates central confluent pulmonary artery in 22-month-old girl thought to have nonconfluent central pulmonary artery by preoperative cineangiogram. This patient underwent RV-PA $10 \mathrm{~mm}$ Dacron conduit insertion as initial palliative operation. Complete repair was done at age 26 months with $P_{R V / L V}$ of 0.62 . B, MRI view demonstrates absence of centrally confluent pulmonary artery. This patient underwent attempt at primary unifocalization procedure but died of inadequate pulmonary blood flow.

teries not visualized by preoperative cineangiograms (Fig. $1, A)$. In one patient, MRI confirmed the presence of nonconfluent central pulmonary arteries noted by preoperative cineangiogram (Fig. 1, $B$ ). The mean diameters of the right and left pulmonary arteries were $2.2 \pm 0.7 \mathrm{~mm}$ (range 1 to $3.0 \mathrm{~mm}$ ) and $1.9 \pm 0.8 \mathrm{~mm}$ (range 0.5 to 3.0 $\mathrm{mm}$ ), respectively (Fig. 2). Pulmonary artery size was determined by preoperative cineangiograms obtained in all patients and corrected for magnification. In those patients in whom preoperative cineangiograms failed to adequately visualize central pulmonary arteries and accurate sizes could not be determined, measurements of the 


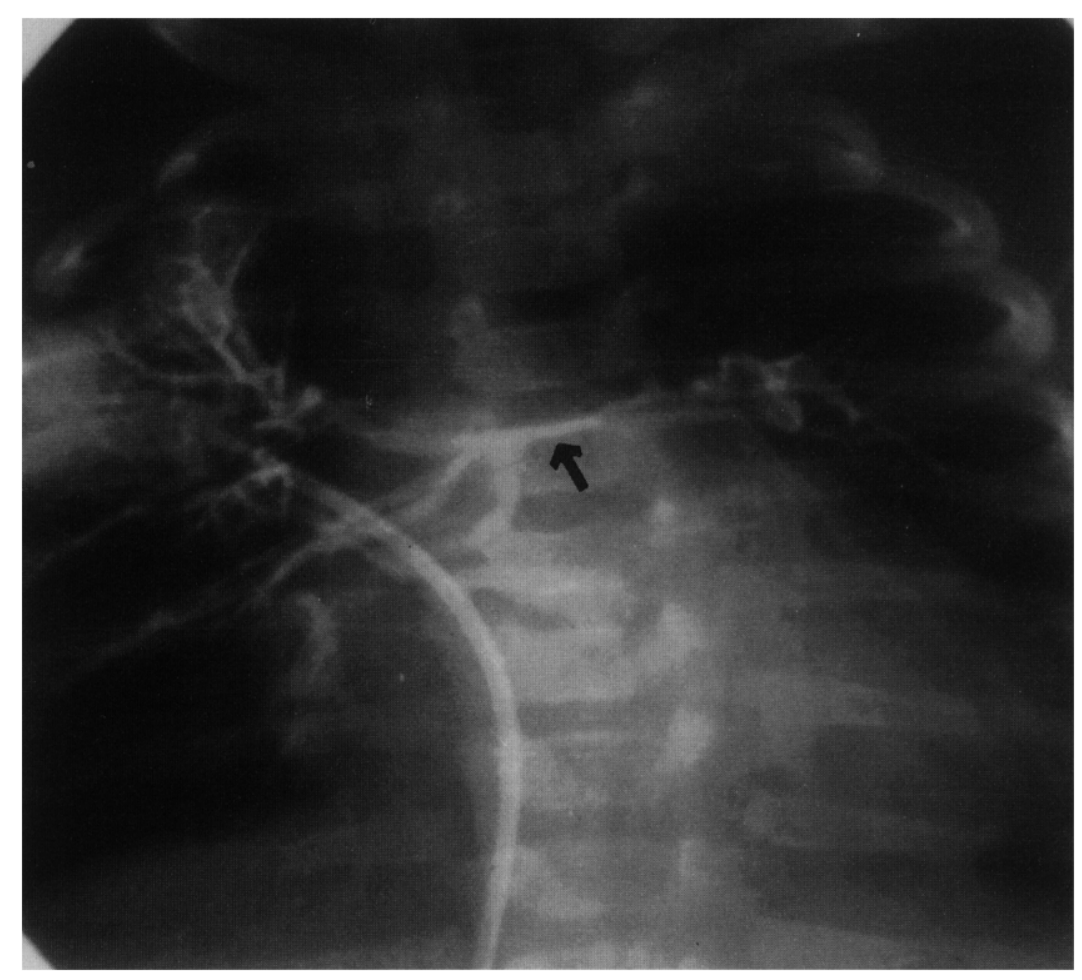

Fig. 2. Right upper pulmonary venous wedge injection in 2.5 -month-old infant demonstrates diminutive pulmonary artery anatomy representative of patients in our group. Confluent central pulmonary artery (arrow), 1 to $1.5 \mathrm{~mm}$, is seen along with apparent abnormalities in distribution of pulmonary arteries to peripheral lung segments. After establishment of antegrade pulmonary artery flow (direct Ao-PA anastomosis (age 6 months), placement of RV-PA conduit (age 15 months)), and performance of multiple interventional procedures, this child underwent complete repair at age 28 months without need for unifocalization procedure. Intraoperative postrepair $P_{R V / L V}$ was 0.45 .

Table III. Initial palliative operative cardiac procedures in 14 patients with TOF/PA and diminutive pulmonary arteries

\begin{tabular}{ll}
\hline \multicolumn{1}{c}{ Initial operative procedure } & No. \\
\hline Aortopulmonary shunt & \\
Modified right Blalock-Taussig shunt & 1 \\
Central aortopulmonary shunt & 2 \\
Unifocalization & 1 \\
Transannular right ventricular outflow patch & 1 \\
Direct Ao-PA anastomosis & 4 \\
RV-PA conduit & 5 \\
\hline
\end{tabular}

pulmonary arteries obtained at initial operation were used. Multiple aortopulmonary collateral arteries were present in all patients (range 1 to 4 vessels) and supplied a variable number of lung segments.

Outcomes. The follow-up inquiry was done between January 1 and April 1, 1995, by review of hospital records, catheterization data, and contact with referring physicians or parents. Information on survival status, hemodynamic status, and functional status obtained by interview with referring physicians or parents was obtained in all pa-
Table IV. Subsequent operative cardiac procedures done in eight patients with TOF/PA and diminutive pulmonary arteries

\begin{tabular}{lc}
\hline \multicolumn{1}{c}{ Operative cardiac procedure } & No. \\
\hline Aortopulmonary shunt revision & 1 \\
Unifocalization & 1 \\
RV-PA conduit & 3 \\
RV-PA conduit revision & 2 \\
Revision of left pulmonary artery stenosis & 1 \\
Ventricular septal defect closure & 8 \\
\hline
\end{tabular}

tients. Determination of the causes of death was made by review of hospital records and autopsy reports (obtained in 4 of 5 deaths).

Data analysis. Data are presented as the mean plus or minus one standard deviation. Comparisons between groups were made with the Student's $t$ test for unpaired observations. Survival was computed by the Kaplan-Meier method and done with the use of proprietary software (Statview, Abacus Concepts, Inc., Berkeley, Calif.). Statistically significant differences were defined at $p<0.05$. 
Volume 110, Number 5

Table V. Summary of operative procedures and outcome in 14 patients with TOF/PA and diminutive pulmonary arteries

\begin{tabular}{|c|c|c|c|}
\hline & $\begin{array}{c}\text { All } \\
\text { patients }\end{array}$ & $\begin{array}{l}\text { Complete } \\
\text { repair }\end{array}$ & $\begin{array}{c}\text { Awaiting } \\
\text { complete } \\
\text { repair }\end{array}$ \\
\hline No. of patients & 14 & 8 & 6 \\
\hline Weight $(\mathrm{kg})$ at initial operation (range) & $\begin{array}{l}8.2 \pm 13.6 \\
(1.7-54.8)\end{array}$ & $\begin{array}{l}5.0 \pm 3.2 \\
(1.7-11.6)\end{array}$ & $\begin{array}{c}12.5 \pm 20.7 \\
(2.8-54.8)\end{array}$ \\
\hline Systemic oxygen saturation $(\%)$ at initial operation (range) & $\begin{array}{l}78 \pm 9 \\
(65-95)\end{array}$ & $\begin{array}{l}77 \pm 10 \\
(65-95)\end{array}$ & $\begin{array}{l}80 \pm 4 \\
(76-84)\end{array}$ \\
\hline Age in months at initial operation (range) & $\begin{array}{c}15.0 \pm 39.2 \\
(0.23-155.1)\end{array}$ & $\begin{array}{r}5.3 \pm 6.8 \\
(0.23-22.2)\end{array}$ & $\begin{array}{r}27.9 \pm 56.9 \\
(0.27-155.1)\end{array}$ \\
\hline Age in months at complete repair (range) & & $\begin{array}{r}18.8 \pm 9.7 \\
(1.1-28.5)\end{array}$ & \\
\hline No. of operative cardiac procedures & 30 & 23 & 7 \\
\hline With CPB & 19 & 13 & 6 \\
\hline With DHCA & 7 & 7 & 0 \\
\hline Non-CPB & 4 & 3 & 1 \\
\hline No. of operative procedures/patient (range) & $\begin{array}{c}2.1 \pm 1.1 \\
(1-4)\end{array}$ & $\begin{array}{c}2.9 \pm 0.8 \\
(2-4)\end{array}$ & $\begin{array}{c}1.1 \pm 0.3 \\
(1-2)\end{array}$ \\
\hline Operative deaths & 2 & 0 & 2 \\
\hline In-hospital deaths & 1 & 1 & 0 \\
\hline Late deaths & 2 & 1 & 1 \\
\hline Number surviving & 9 & 6 & 3 \\
\hline
\end{tabular}

$C P B$, Cardiopulinonary bypass; $D H C A$, deep hypothermic circulatory arrest.

\section{Results}

The initial palliative operative procedures done in the 14 patients are listed in Table III. The most frequent initial procedure was insertion of an RV-PA conduit ( $36 \%$ ), followed by direct ascending aorta-pulmonary artery (Ao-PA) anastomosis (29\%), aortopulmonary shunt $(21 \%)$, primary unifocalization procedure $(7 \%)$, and transannular right ventricular outflow patch $(7 \%)$. Subsequent operative procedures were done in eight patients and are listed in Table IV. Thus a total of 30 operative cardiovascular procedures were done in 14 patients (Table V). Of these 30 procedures, $63 \%$ were done with cardiopulmonary bypass (mean cardiopulmonary bypass time $138 \pm 53$ minutes, range 55 to 243 minutes; mean aortic crossclamp time $73 \pm 31$ minutes, range 25 to 112 minutes), $23 \%$ were done with hypothermic circulatory arrest (mean circulatory arrest time $30 \pm 20$ minutes, range 6 to 66 minutes), and $13 \%$ were done without cardiopulmonary bypass (shunt, 2; shunt revision, 1 ; unifocalization procedure, 1 ).

Six of 14 patients had one or multiple additional interventional procedures (Table VI). These procedures included intraoperative (concomitant with other operative cardiovascular procedures) insertion of intravascular pulmonary artery stents in four patients, coil embolization of multiple aortopulmonary collateral arteries ( 3 interventional catheteriza-
Table VI. Summary of interventional procedures in 14 patients with TOF/PA and diminutive pulmonary arteries

\begin{tabular}{|c|c|c|c|}
\hline & $\begin{array}{c}\text { All } \\
\text { patients }\end{array}$ & $\begin{array}{l}\text { Complete } \\
\text { repair }\end{array}$ & $\begin{array}{l}\text { Awaiting } \\
\text { complete } \\
\text { repair }\end{array}$ \\
\hline No. of patients & 14 & 8 & 6 \\
\hline $\begin{array}{l}\text { No. of patients un- } \\
\text { dergoing interven- } \\
\text { tional procedure }\end{array}$ & $6(43 \%)$ & $6(75 \%)$ & 0 \\
\hline $\begin{array}{l}\text { No. of interventional } \\
\text { procedures }\end{array}$ & 12 & 12 & 0 \\
\hline Stent* & 5 & 5 & 0 \\
\hline Embolization $\dagger$ & 3 & 3 & 0 \\
\hline Angioplastył & 4 & 4 & 0 \\
\hline $\begin{array}{l}\text { No. of interventions } \\
\text { per patient } \\
\text { (range) }\end{array}$ & $\begin{array}{c}0.9 \pm 1.1 \\
(0-3)\end{array}$ & $\begin{array}{c}1.5 \pm 1.2 \\
(1-3)\end{array}$ & 0 \\
\hline
\end{tabular}

"Location of stent placements included proximal right pulmonary artery (1 patient), proximal left pulmonary artery ( 1 patient), and bilateral in 2 patients (left upper lobe and right lower lobe pulmonary artery; right lower lobe, proximal and distal left pulmonary artery). A total of seven stents were placed in four patients during five separate procedures.

Three interventional catheterization procedures were done in three patients.

FFour interventional catheterization procedures were done in three patients.

tions in 3 patients), and multiple balloon angioplasties of pulmonary artery stenoses (4 interventional catheterizations in 3 patients).

Of the 14 patients in this study, eight $(57 \%)$ have subsequently received complete repair (Fig. 3). At 

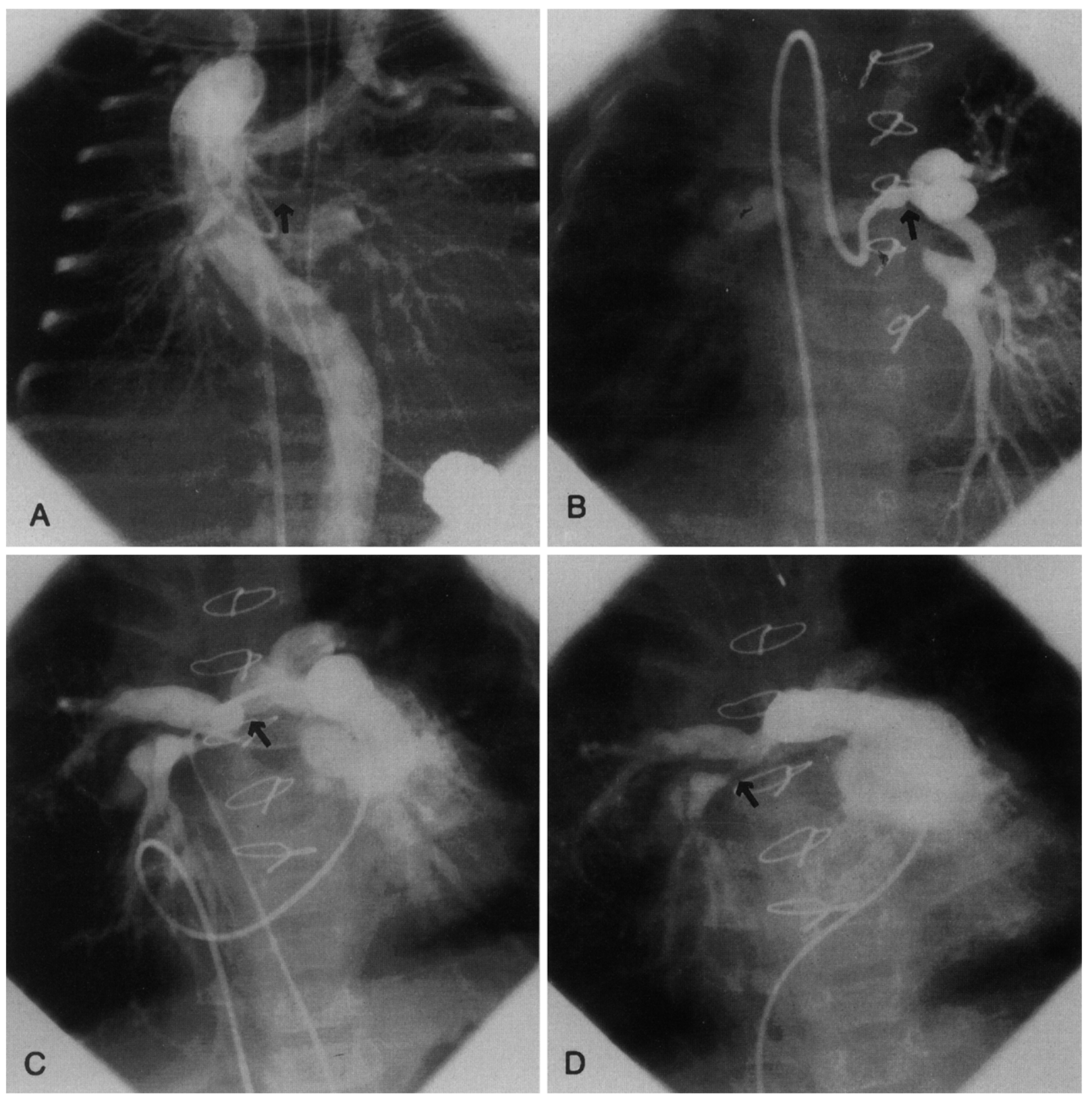

Fig. 3. A, Aortic contrast injection demonstrates diminutive confluent central pulmonary arteries (arrow) in 2-day-old premature neonate (32 weeks' gestation, weight $1.66 \mathrm{~kg}$ ) with tetralogy of Fallot and pulmonary atresia. Pulmonary artery measured $1.5 \mathrm{~mm}$ on right and less than $1.0 \mathrm{~mm}$ on left. Direct Ao-PA anastomosis was done at age 22 days. B, Contrast injection in orifice of aortopulmonary anastomosis in same patient at age 10 months. There is proximal right pulmonary artery stenosis with faint filling of contrast within right pulmonary artery and stenosis of left pulmonary artery (arrow). RV-PA conduit was inserted at 1 year of age. $\mathbf{C}$, Contrast injection into RV-PA conduit in same patient at age 22 months. Note persistent right pulmonary artery stenosis (arrow). D, Contrast injection into RV-PA conduit at age 22 months after balloon angioplasty of proximal right pulmonary artery stenosis. There is improvement in degree of proximal right pulmonary artery stenosis, but there remains significant right lower lobe pulmonary artery stenosis (arrow). Complete repair with ventricular septal defect closure was done at age 27 months. At time of complete repair, left upper lobe and right lower lobe intravascular stents were placed with successful dilation of these peripheral stenoses. Intraoperative postrepair peak $\mathrm{P}_{\mathrm{RV} / \mathrm{LV}}$ was 0.55 . 


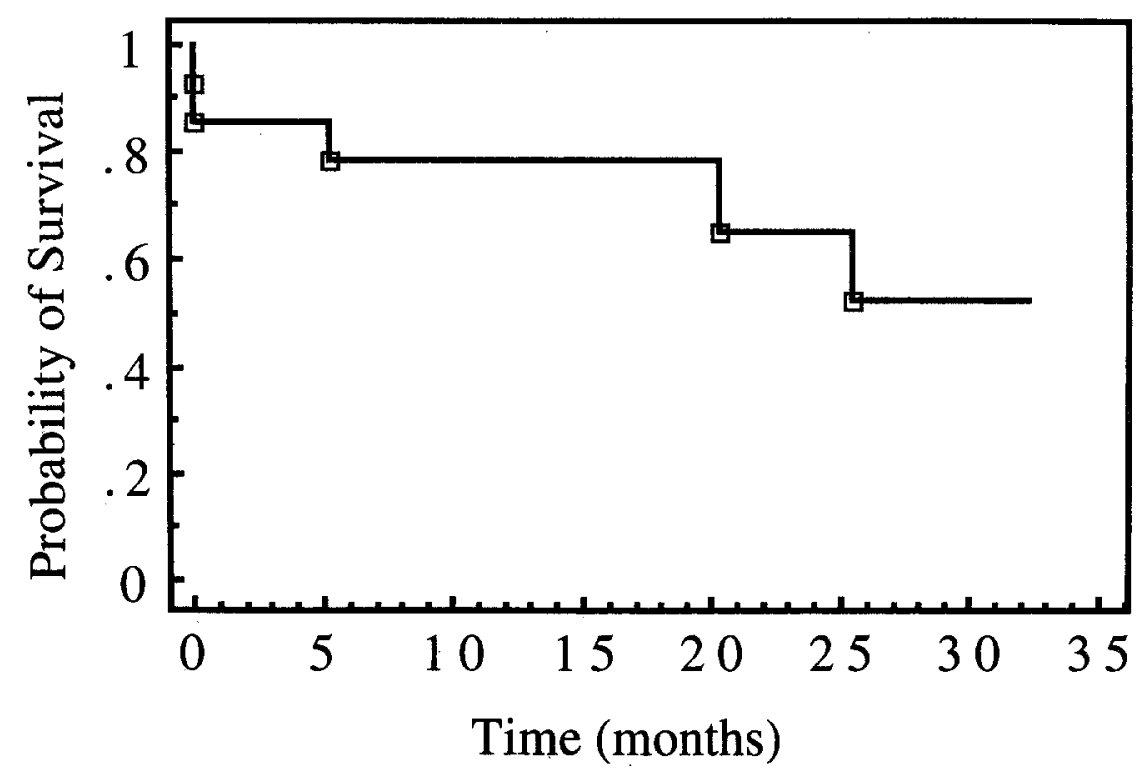

Fig. 4. Kaplan-Meier estimate of overall cumulative survival for all patients $(n=14)$ from time of initial palliative operative procedure.

the time of complete repair, all patients had closure of the ventricular septal defect and insertion of an RV-PA cryopreserved pulmonary allograft conduit (size range 17 to $21 \mathrm{~mm}$ ). Intraoperative postrepair peak right ventricle-left ventricle pressure ratio $\left(\mathrm{P}_{\mathrm{RV} / \mathrm{LV}}\right.$ ) was $0.57 \pm 0.18$ (range 0.34 to 0.9 ). Mean follow-up from the time of complete repair was $8.9 \pm 8.2$ months (range 0.5 to 23.8 months). At the time of follow-up inquiry, five of six surviving patients were less than the 5 th percentile for height and weight (corrected for prematurity), whereas one patient was less than the 5 th percentile for weight and less than the 10th percentile for height. Mean room air systemic arterial oxygen saturation was $95 \% \pm 1 \%$. Four patients continued to receive digoxin and diuretic therapy, one patient received digoxin therapy alone, and one patient received diuretic therapy only. Four of the six patients were receiving aspirin therapy because of intravascular pulmonary artery stents. All remained active with no physical limitations. At the time of follow-up, two of six patients had further planned catheterizations for additional dilation of peripheral pulmonary artery stenoses.

There are three surviving patients awaiting further operative procedures to achieve complete repair. Two patients in this group had values greater than the 75 th percentile for height and weight at the time of follow-up inquiry, and one patient remained less than the 5th percentile for height and weight. Mean room air systemic arterial oxygen saturation was $83 \% \pm 9 \%$. All were receiving digoxin and diuretic therapy and remained suitable candidates for continued staged repair.

Neurologic outcome. Five neurologic complications were observed in 4 of 14 patients after a total of 30 operative procedures. These complications included encephalopathy (2), seizures (2), and anoxic brain injury (1). The anoxic brain injury occurred postoperatively after resuscitation from an episode of ventricular fibrillatory arrest. Resolution of the neurologic complications occurred in all other instances.

Survival analysis. Operative mortality for the entire group was 14\% (2/14 patients) (Table V). An infant with discontinuous central pulmonary arteries and severe hypoplasia of the left pulmonary artery $(0.5 \mathrm{~mm})$ died shortly after a primary unifocalization procedure because of inadequate pulmonary blood flow. The second operative death was attributable to low cardiac output in an infant with associated congenital aortic stenosis, who died on postoperative day 1 after a direct Ao-PA anastomosis. There was one in-hospital death at 45 days after complete repair from neurologic (microcephaly) and septic complications. There was one late noncardiac death at 5.3 months after insertion of a transannular right ventricular outflow patch caused by closed blunt 


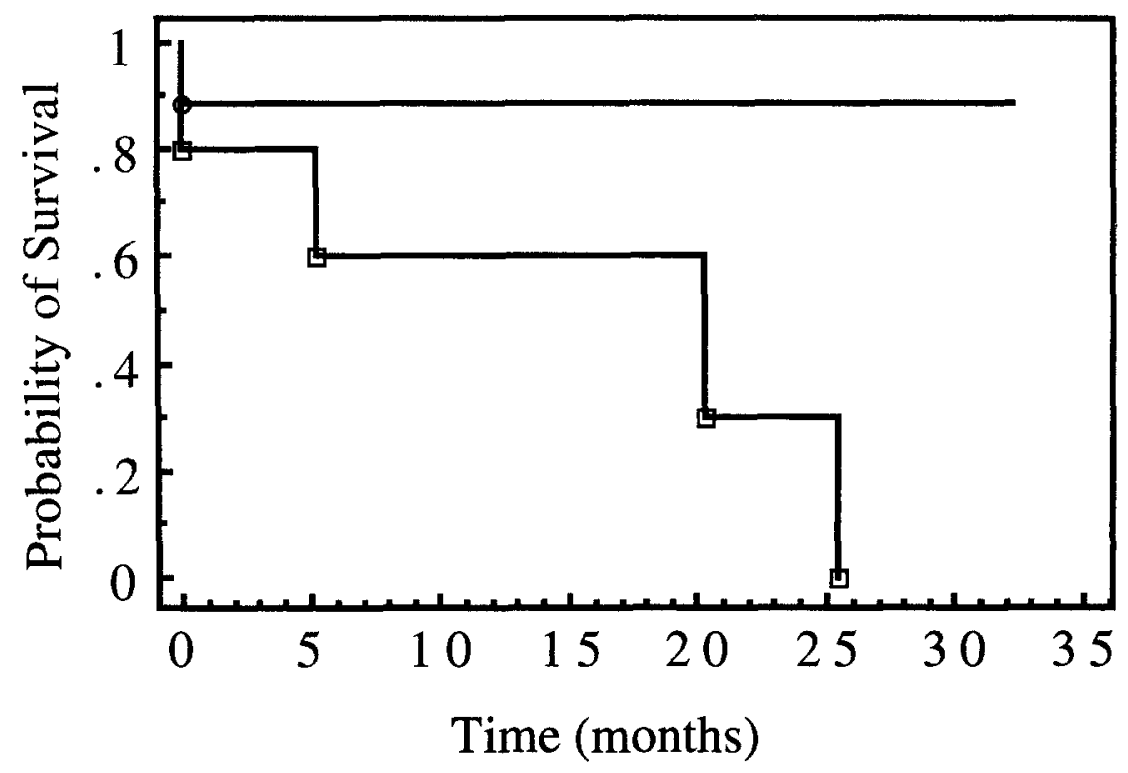

Fig. 5. Comparison of Kaplan-Meier estimate of overall cumulative survival for patients having either RV-PA conduit or direct Ao-PA anastomosis as initial palliative operative procedure (circles, $n=9)$ or other palliative operative procedure (shunt, transannular right ventricular outflow patch, or unifocalization procedure; squares, $n=5$ ).

head trauma (confirmed at autopsy). One late cardiac death occurred at 20.3 months after complete repair after reoperation for conduit stenosis and was attributable to severe anoxic brain injury after an episode of ventricular fibrillatory arrest.

Mean follow-up for all patients from the time of initial operative procedure was $17.3 \pm 10.9$ months (range 0 to 32.2 months). Overall cumulative survival from the initial operative procedure for all patients was $48 \%$ at 32.2 months (Kaplan-Meier estimate, Fig. 4).

Analysis of outcome based on initial procedure. Of the five deaths in this series, four $(80 \%)$ occurred in patients who received either shunts (central, 2; modified Blalock-Taussig, 1), transannular patch (1), or unifocalization (1) as the initial procedure. Among the patients who underwent these procedures as the initial palliation, only one is alive with a complete repair. In contrast, there was only one death among nine patients $(11 \%)$ who received either an RV-PA conduit (5) or direct Ao-PA anastomosis (4) as the initial operative procedure. Five $(56 \%)$ ) of these nine patients have subsequently received complete repair with no deaths. Overall cumulative survival for the nine patients who had either RV-PA conduit or direct Ao-PA anastomosis as the initial palliative operation was $89 \%$ at 32.2 months (Kaplan-Meier estimate, Fig. 5). Overall cumulative survival for patients who had other procedures as the initial palliative operation was $0 \%$ at 25.5 months (Kaplan-Meier estimate, Fig. 5).

\section{Discussion}

The purpose of this study was to review our treatment of children with TOF/PA and severely diminutive pulmonary arteries (diameter $\leq 3 \mathrm{~mm}$ ). Although patients with this anomaly may have a wide spectrum of pulmonary artery segmentation abnormalities, stenoses, and hypoplasia, it is this group that challenges the current treatment strategies. The patients in our study represent a reasonably homogeneous population having the characteristics of diminutive confluent central pulmonary arteries $(93 \%)$, aortopulmonary collateral arteries in all patients, absent ductus arteriosus $(79 \%)$, and young age at initial palliative operation (age $<6.2$ months in $86 \%, 12 / 14$ patients) and at complete repair (age $<28.5$ months in all patients). Despite the size of the pulmonary arteries and young age of the patients in this series, sufficient recruitment and rehabilitation of the pulmonary arteries was achieved without unifocalization procedures to allow complete repair with ventricular septal defect closure in $57 \%$ of patients $(8 / 14)$. The three additional surviving patients appear to be satisfactory candidates for complete repair, and only one has required a unifocalization procedure. 
In a recent study consisting of patients similar to those in our own patient group, Rome and colleagues ${ }^{10}$ reported on 48 patients with TOF/PA and diminutive pulmonary arteries. Of these 48 patients, 20 (mean age 1.6 years) had RV-PA continuity established, followed by subsequent coil embolization of aortopulmonary collateral arteries and dilation of pulmonary artery stenoses, as needed. Twelve patients $(60 \%)$ went on to complete repair, with an overall mortality rate for the group of $35 \%$.

Successful treatment of this condition requires the achievement of right ventricle-dependent pulmonary blood flow to a sufficient number of unobstructed bronchopulmonary segments. ${ }^{16}$ When this goal is not achieved, long-term prognosis is poor. ${ }^{1,2}$ However, debate continues regarding the best management strategies to achieve this outcome. When pulmonary artery size is large, particularly in the presence of a ductus arteriosus, arborization anomalies are uncommon and complete repair is likely. However, in patients with extremely small pulmonary arteries, absence of the ductus, and multiple aortopulmonary collateral arteries, initial operative approaches have included systemic-pulmonary artery shunts, ${ }^{17,}{ }^{18}$ RV-PA conduits, ${ }^{19-22}$ and unifocalization procedures. ${ }^{4,5,23}$ Often, no intervention is selected because of a perceived small likelihood of ever achieving satisfactory complete repair. Although this latter approach was believed by some to be the most appropriate in two of our patients because of extremely small pulmonary artery and body size $(1.66 \mathrm{~kg}$, pulmonary arteries $1 \mathrm{~mm} ; 2.27$ $\mathrm{kg}$, pulmonary arteries $0.9 \mathrm{~mm}$ ), both patients have had satisfactory complete repairs with a postoperative $\mathrm{P}_{\mathrm{RV} / \mathrm{LV}}$ of less than 0.55 (Fig. 3).

Our approach in the treatment of TOF/PA and diminutive pulmonary arteries, as reported by others, ${ }^{10}$ has been to establish RV-PA continuity, generally by age 3 months. Early antegrade pulmonary artery flow serves to promote growth of the central and hilar pulmonary vessels, improve systemic arterial oxygen saturation, and allow subsequent access for diagnostic catheterization procedures to better define pulmonary artery anatomy. Interventional procedures including coil embolization of aortopulmonary collateral arteries, balloon dilation of peripheral pulmonary artery stenoses, and insertion of intravascular pulmonary artery stents are done as necessary to maximize the distribution of pulmonary artery blood flow to the greatest number of unobstructed bronchopulmonary segments. Decisions regarding complete repair can then be based on more
Table VII. Pulmonary artery sizes in patients undergoing either $R V-P A$ conduit or direct Ao-PA anastomosis as the initial palliative operative procedure

\begin{tabular}{lcc}
\hline & $\begin{array}{c}\text { Right } \\
\text { pulmonary } \\
\text { artery diameter } \\
(\mathrm{mm})\end{array}$ & $\begin{array}{c}\text { Left pulmonary } \\
\text { artery diameter } \\
(\mathrm{mm})\end{array}$ \\
\hline $\begin{array}{c}\text { Initial palliative procedure } \\
(n=4)\end{array}$ & $1.4 \pm 0.3$ & $1.2 \pm 0.2$ \\
RV-PA conduit $(n=5)$ & $2.8 \pm 0.6^{*}$ & $2.5 \pm 0.5^{*}$ \\
\hline
\end{tabular}

$*_{p}<0.05$ as compared with respective pulmonary artery size in four patients having a direct Ao-PA anastomosis.

meaningful physiologic data, such as degree of leftto-right shunting (optimally a pulmonic to systemic flow ratio of $\geq 1.5)^{24}$ through the ventricular septal defect, rather than pulmonary artery size or presumed number of centrally perfused bronchopulmonary segments.

The limiting factor in establishing early RV-PA continuity has been the size of the central pulmonary arteries. With confluent central pulmonary arteries smaller than approximately $1.5 \mathrm{~mm}$, we have found it technically difficult to place a conduit and have favored construction of a direct Ao-PA anastomosis as the initial procedure, reserving insertion of an RV-PA conduit until later. ${ }^{25}$ This approach has the advantage of avoiding both a thoracotomy and a peripheral anastomosis along the pulmonary artery, which may result in more distortion. If a unifocalization procedure is ultimately required, it can be done in a pleural space free of adhesions, connecting the collateral artery or arteries to a right or left central pulmonary artery that has been enlarged by the initial operation or by subsequent ballon dilation. In cases in which the central pulmonary artery size is greater than $1.5 \mathrm{~mm}$, insertion of an RV-PA conduit has been technically successful and is the preferred initial procedure (Table VII). We prefer to use a nonvalved Dacron conduit, reserving cryopreserved pulmonary allografts for conduit replacement at the time of complete repair. When pulmonary allografts are used in this setting and are exposed to systemic pressure, aneurysmal dilation of the allograft has been observed and theoretically may reduce the transmission of kinetic energy forces from the heart to the pulmonary arteries.

With use of the current treatment strategy, the need for unifocalization procedures in management of TOF/PA may be reduced. Concerns have been 
raised regarding the long-term efficacy of unifocalization and reliability of basing pulmonary blood flow on aortopulmonary collateral arteries that contain a variable degree of muscular or musculoelastic segments that may develop intimal proliferation and stenoses. ${ }^{6}$ There will remain a subset of patients who require unifocalization procedures to allow complete repair, but these procedures are better left until after RV-PA continuity is established. ${ }^{26}$ These patients are likely to be those with nonconfluent pulmonary arteries in whom the prevalence of significant incomplete arborization of the hilar pulmonary vessels approximates $80 \% .{ }^{27}$ However, the prevalence of congenital nonconfluence in the presence of diminutive pulmonary arteries is low: $3 \%$ in the report by Alfieri and colleagues, ${ }^{19} 15 \%$ in the series of Sullivan and colleagues, ${ }^{9} 16 \%$ in the series of Shimazaki and colleagues, ${ }^{27}$ and $7 \%$ (1/14 patients) in our study. Additionally, the prevalence of significant incomplete arborization of the pulmonary arteries in the setting of centrally confluent arteries is relatively low, with at least $80 \%$ in one series of patients with TOF/PA and confluent central pulmonary arteries having pulmonary blood flow to 15 or more pulmonary segments. ${ }^{27}$ In an autopsy series of hearts with TOF/PA, Anderson, Devine, and Del Nido ${ }^{28}$ reported that 11.8 segments received blood flow from central pulmonary arteries, 5.1 segments received blood flow from aortopulmonary collateral arteries only, and 0.64 segments received blood flow from a dual source. Thus, on average, nearly 13 segments received blood from central pulmonary arteries. When 15 or more pulmonary segments are connected to the central pulmonary circulation, the addition of a unifocalization procedure to incorporate additional pulmonary segments adds little to the overall reduction in pulmonary artery resistance. ${ }^{16}$ Furthermore, dual supply from both the central pulmonary arteries and the systemic collateral arteries, which may be difficult to demonstrate on the initial studies, may become evident when a pulmonary angiogram is done through the conduit with balloon occlusion of the aortopulmonary collateral artery.

An important factor in determining the type of initial operative procedure in patients with TOF/PA is the presence of confluent central pulmonary arteries. Thus accurate preoperative assessment of the morphologic features of the pulmonary arteries is essential. In two patients in our study, preoperative cineangiograms failed to adequately demonstrate confluence of the central pulmonary arteries, despite selective angiograms within aortopulmonary collateral arteries or pulmonary venous wedge injections. In both patients, MRI studies identified confluent central pulmonary arteries not seen by angiography. Thus the initial operative procedure was an RV-PA conduit in one infant and a direct Ao-PA anastomosis in the other infant, rather than a primary unifocalization procedure. In one additional patient, an MRI study correctly identified nonconfluent pulmonary arteries. Recent studies have confirmed our observations that MRI provides an accurate and complementary role to angiography in the evaluation of pulmonary atresia and diminutive pulmonary arteries. ${ }^{29,30}$

Accurately defining the extent of arborization anomalies of the pulmonary arteries is difficult during preoperative assessment of TOF/PA because of the inability to gain access to the central pulmonary arteries for proper imaging and the presence of peripheral pulmonary artery stenoses. The anatomy of the hilar pulmonary vessels may be better defined, and the need for unifocalization may be more thoroughly assessed, delayed, or even avoided if right ventricle-dependent pulmonary blood flow is first established and then subsequently followed up by selective pulmonary angiograms and dilation of pulmonary artery stenoses. Although early initial unifocalization procedures are advocated by some groups, it is our belief that the frequency and magnitude of unifocalization procedures can be reduced and deferred until after RV-PA continuity is established.

There are a number of limitations to our study. First, this report is a retrospective review of our institutional approach to the management of this congenital malformation, and the patients were not treated according to a randomized protocol. Second, because of selection of a rather homogeneous, but high-risk, group of patients with TOF/PA, the number of patients in our study is small. This limits us in performing meaningful statistical comparisons between subgroups of patients and in drawing specific inferences regarding the best management approach. The question of whether an initial palliative procedure other than insertion of an RV-PA conduit or direct Ao-PA anastomosis is a risk factor for death cannot be answered by this study. The marked differences in survival noted between groups receiving either an RV-PA conduit or a direct Ao-PA anastomosis as compared with another initial procedure (Fig. 5) may be related to risk factors such as associated congenital malformations or nonconflu- 
ence of the pulmonary arteries and not necessarily to the type of initial palliative procedure. However, despite these limitations, this approach has facilitated a satisfactory definitive repair in a substantial percentage of patients $(57 \%)$ without the need for unifocalization procedures, at a relatively young age ( $<28.5$ months in all patients), and with satisfactory intermediate follow-up.

\section{REFERENCES}

1. Kirklin JW. Ventricular septal defect and pulmonary stenosis or atresia. In: Kirklin JW, Barratt-Boyes BG, eds. Cardiac surgery. 2nd ed. New York: Churchill Livingstone, 1993:861-1012.

2. Kirklin JW, Blackstone EH, Shimazaki Y, et al. Survival, functional status, and reoperations after repair of tetralogy of Fallot with pulmonary atresia. J Thorac Cardiovasc Surg 1988;96:102-16.

3. Puga FJ. Unifocalization for pulmonary atresia with ventricular septal defect. Ann Thorac Surg 1991;51:8-9.

4. Puga FJ, Leoni FE, Julsrud PR, Mair DD. Complete repair of pulmonary atresia, ventricular septal defect, and severe peripheral arborization abnormalities of the central pulmonary arteries: experience with preliminary unifocalization procedures in 38 patients. $\mathbf{J}$ Thorac CaRdiovasC Surg 1989;98:1018-29.

5. Sawatari K, Imai $Y$, Kurosawa H, Isomatsu Y, Momma K. Staged operation for pulmonary atresia and ventricular septal defect with major aortopulmonary collateral arteries: new technique for complete unifocalization. J Thorac Cardiovasc Surg 1989;98:738-50.

6. DeRuiter MC, Gittenberger-de Groot AC, Bogers A, Elzenga NJ. The restricted surgical relevance of morphologic criteria to classify systemic-pulmonary collateral arteries in pulmonary atresia with ventricular septal defect. J Thorac Cardiovasc Surg 1994;108:692-9.

7. Haworth SG. Collateral arteries in pulmonary atresia with ventricular septal defect: a precarious blood supply. Br Heart J 1980;44:5-13.

8. Haworth SG, Macartney FJ. Growth and development of pulmonary circulation in pulmonary atresia with ventricular septal defect and major aortopulmonary collateral arteries. Br Heart J 1980;44:14-24.

9. Sullivan ID, Wren C, Stark J, de Laval MR, Macartney FJ, Deanfield JE. Surgical unifocalization in pulmonary atresia and ventricular septal defect: a realistic goal? Circulation 1988;78(5 Pt 2):III5-13.

10. Rome JJ, Mayer JE, Castaneda AR, Lock JE. Tetralogy of Fallot with pulmonary atresia: rehabilitation of diminutive pulmonary arteries. Circulation 1993;88( $\mathrm{Pt}$ I):1691-8.

11. Lock JE, Castaneda-Zuniga WR, Fuhrman BP, Bass JL. Balloon dilation angioplasty of hypoplastic and stenotic pulmonary arteries. Circulation 1983;67:962-7.

12. Ring JC, Bass JL, Marvin W, et al. Management of congenital stenosis of a branch pulmonary artery with balloon dilation angioplasty: report of 52 cases. J Thorac Cardiovasc Surg 1985;90:35-44.

13. Perry SB, Radtke W, Fellows KE, Keane JF, Lock JE. Coil embolization to occlude aortopulmonary collateral vessels and shunts in patients with congenital heart disease. J Am Coll Cardiol 1989;13: 100-8.

14. Zahn EM, Lima VC, Benson LN, Freedom RM. Use of endovascular stents to increase pulmonary blood flow in pulmonary atresia with ventricular septal defect. Am J Cardiol 1992;70:411-2.

15. Mendelsohn AM, Bove EL, Lupinetti FM, et al. Intraoperative and percutaneous stenting of congenital pulmonary artery and vein stenosis. Circulation 1993;88(5 Pt 2):II210-7.

16. Shimazaki Y, Tokuan Y, Lio M, et al. Pulmonary artery pressure and resistance late after repair of tetralogy of Fallot with pulmonary atresia. J THORAC Cardiovasc Surg 1990;100:425-40.

17. Kirklin JW. Growth of the pulmonary anulus and pulmonary arteries after Blalock-Taussig shunt. J Thorac Cardiovasc Surg 1979;77:459-65.

18. Haworth SG, Rees PG, Taylor JF, Macartney FJ, de Leval M, Stark J. Pulmonary atresia with ventricular septal defect and major aortopulmonary collateral arteries: effect of systemic pulmonary anastomosis. $\mathrm{Br}$ Heart J 1981;45:133-41.

19. Alfieri O, Blackstone EH, Kirklin JW, Pacifico AD, Bargeron LM. Surgical treatment of tetralogy of Fallot with pulmonary atresia. J THORAC CARDIOVASC SURG 1978; 76:321-35.

20. Millikan JS, Puga FJ, Danielson GK, Schaff HV, Julsrud PR, Mair DD. Staged surgical repair of pulmonary atresia, ventricular septal defect, and hypoplastic, confluent pulmonary arteries. J THORAC Cardiovasc Surg 1986;91:818-25.

21. Piehler JM, Danielson GK, McGoon DC, Wallace RB, Fulton RE, Mair DD. Management of pulmonary atresia with ventricular septal defect and hypoplastic pulmonary arteries by right ventricular outflow construction. $J$ Thorac Cardiovasc Surg 1980;80:552-67.

22. Freedom RM, Pongiglione G, Williams WG, Trusler GA, Rowe RD. Palliative right ventricular outflow tract construction for patients with pulmonary atresia, ventricular septal defect, and hypoplastic pulmonary arteries. J THORAC CARdrovasC SURG 1983;86:24-36.

23. Iyer KS, Mee RBB. Staged repair of pulmonary atresia with ventricular septal defect and major systemic to pulmonary artery collaterals. Ann Thorac Surg 1991;51:65-72.

24. de Leval M. Pulmonary atresia and ventricular septal defect. In: Stark J, de Laval M, eds. Surgery for congenital heart defects. 2nd ed. Philadelphia: WB Saunders, 1994;417-28.

25. Watterson KG, Wilinson JL, Karl TR, Mee RBB. 
Very small pulmonary arteries: the central end-to-end side shunt. Ann Thorac Surg 1991;52:1132-7.

26. Shanley CJ, Lupinetti FM, Shah NL, Beekman RH III, Crowley DC, Bove EL. Primary unifocalization for the absence of intrapericardial pulmonary arteries in the neonate. J Thorac Cardiovasc Surg 1993;106:237-47.

27. Shimazaki Y, Maehara T, Blackstone EH, Kirklin JW, Bargeron LM. The structure of the pulmonary circulation in tetralogy of Fallot with pulmonary atresia: a quantitative cineangiographic study. J THORAC CARDIOVASC SURG 1988;95:1048-58.

28. Anderson RH, Devine WA, Del Nido P. The surgical anatomy of tetralogy of Fallot with pulmonary atresia rather than pulmonary stenosis. J Card Surg 1991;6:4159.

29. Canter CE, Guitierrez FR, Mirowitz SA, Martin TC, Hartmann AF Jr. Evaluation of pulmonary arterial morphology in cyanotic congenital heart disease by magnetic resonance imaging. Am Heart J 1989;118: 347-54.

30. Rees RS, Somerville J, Underwood SR, et al. Magnetic resonance imaging of the pulmonary arteries and their systemic connections in pulmonary atresia: comparison with angiographic and surgical findings. Br Heart J 1987;58:621-6.

\section{Discussion}

Dr. John E. Mayer (Boston, Mass.). We also have been interested in treating this group of patients with TOF $/ \mathrm{PA}$ and diminutive pulmonary arteries, and we have adopted a similar approach of attempting to restore antegrade pulmonary blood flow to the central pulmonary arteries as an initial palliation followed by subsequent balloon dilation of distal pulmonary artery stenoses and either coil occlusion of aortopulmonary collateral arteries or unifocalization procedures to recruit additional areas of pulmonary parenchyma into continuity with the central pulmonary arteries before or at the time of ventricular septal defect closure.

Our results over the period 1985 to 1994 are quite similar to those presented by Dr. Pagani. We had 78 patients whom we treated with an initial palliation, and the vast majority of the procedures were RV-PA conduits. Two patients had a right ventricular outflow tract patch as the initial procedure.

We have been able to achieve ventricular septal defect closure in more than half of these patients, and 10 additional patients are awaiting ventricular septal defect closure or additional interventional catheterizations, or both. In those who have had the ventricular septal defect closed, 24 have come back for follow-up studies and have a mean $P_{R V / L V}$ that is quite similar to that reported by the Michigan group.

I have only a few questions. First, I noticed that the patients who have not undergone repair seemed to have been older at the time of the first intervention on average than patients in the group who have undergone repair. Do the authors think that the age at the first intervention is. important, and if so, what do they think is the best time for restoration of blood flow to the central pulmonary arteries?

Second, because the role of interventional cardiologists is so important in the treatment of these patients, particularly with balloon dilations of peripheral pulmonary arteries, I wonder if the authors could tell us whether they have had difficulties in gaining access to the central pulmonary arteries for dilation when the direct aortopulmonary anastomotic technique is used rather than an RV-PA conduit.

Finally, I wonder if the authors could speculate on why the $P_{R V / L V}$ in the patients with the closed ventricular septal defects is not less than 0.6 in both their series and ours. Although we think this ratio is acceptable, I wonder if the authors might speculate on why they think that we do not do better, certainly compared with the results in patients with routine tetralogy of Fallot repair.

Dr. Pagani. In reference to the first question regarding the age of the group of patients who did not undergo repair, we had one child who was 14 years old who skewed the mean age in this small number of patients. The other patients in this group were similar in age to those having complete repair.

With regard to the second question about the ability to gain access through the aortopulmonary anastomosis, no interventional procedures were done through that anastomosis. Diagnostic procedures were done. The choice of proceeding to a direct anastomosis as opposed to an RV-PA conduit was based on the size of the pulmonary artery.

When we looked at the results in those patients who received an RV-PA conduit or a direct anastomosis, as one would suspect, pulmonary artery size was smaller in the latter group. Our preference was for an RV-PA conduit to allow interventional procedures, if possible.

In regard to the third question as to why the $P_{R V / L V}$ remained elevated after complete repair, I suspect unrecognized pulmonary vascular disease and unrecognized areas of stenosis left in the peripheral pulmonary arteries are probably present.

Dr. Richard A. Jonas (Boston, Mass.). When we first started operating on this patient population and were using circulatory arrest quite commonly for insertion of the RV-PA homograft, we had several cases of choreoathetosis and other neurologic problems. Have the authors had problems with neurologic injury in this patient population and can they tell us something about the method that they use for inserting the RV-PA homograft?

Dr. Pagani. In terms of neurologic complications for the group, we had two instances of encephalopathy, two seizures, and one anoxic brain injury that was attributed to fibrillatory arrest.

Dr. Jonas. Those were all different patients?

Dr. Pagani. No, there were about four patients out of the group who had neurologic consequences.

Dr. Jonas. Were those patients all having homografts placed?

Dr. Pagani. No, these were injuries that occurred in the entire group and they were not necessarily related to homograft use.

Dr. Jonas. Were you using cardiopulmonary bypass?

Dr. Pagani. Bypass was used with insertion of the conduit. 
Dr. Jonas. What was the pH strategy used?

Dr. Pagani. Alpha-stat.

Dr. Jan M. Quaegebeur (New York, N.Y.). It is a bit unclear to me, Dr. Pagani, why unifocalization procedures were not necessary. As you know, the distribution of the pulmonary arteries is unequal in these patients and not all segments of the lung are supplied by the two pulmonary artery trees or confluence. Can you explain why it was unnecessary to use in any of your patients operations that would recruit additional pulmonary parenchyma with aortopulmonary collateral arteries?

Dr. Pagani. In the situation in which confluent pulmonary arteries are present, I think that although there are abnormalities in the distribution of the peripheral pulmonary arteries, the abnormalities are not as severe as in the case of nonconfluent pulmonary arteries. About $70 \%$ to $80 \%$ of these patients have at least 15 pulmonary segments supplied by the central pulmonary arteries, so one would not anticipate having severe arborization abnormalities. In a paper by Anderson, Devine, and Del Nido, ${ }^{28}$ nearly 13 segments were perfused. Thus I do not think there were severe arborization abnormalities of the pulmonary arteries in this particular group of patients. Such abnormalities are present, however, because two of our patients required unifocalization procedures. 